\title{
A Gamified System for Task Monitoring and Performance Evaluation Using the Learning Vectors (LV) Model
}

\author{
Michelle G Cacais ${ }^{1}$, Givandenys L Sales ${ }^{1}$, Weslley L Caldas ${ }^{2}$ \\ IFCE - Federal Institute of Education, Science and Technology of Ceará Fortaleza ${ }^{l}$ \\ UFC - Federal University of Ceará Fortaleza ${ }^{2}$ \\ Brazil
}

\begin{abstract}
Nowadays, many people have Internet access, which changes the ways of relationship and communication. Digital technologies emerged as a new paradigm, which changes many aspects of routine. This way, it is important to look for new ways of performing tasks in order to achieve the objectives. Task monitoring and performance evaluation could be great allies in achieving positive results. In order to keep people engaged and committed to their own income, we propose a gamified system that uses the Learning Vector Model for performance evaluation and follow-up of tasks. The system can be applied in entities and companies with the purpose of socializing, motivating or promoting the interaction of users. It was verified through field research, that our system helped with the improvement of the performance of the evaluated team and motivated the professionals. The evaluation using the Learning Vector Model helped in the monitoring and the progress of the evaluated ones. They also could interact more with the work team.
\end{abstract}

\section{Introduction}

With the advancement of technology and the changing habits of population, society is becoming increasingly complex. Nowadays, many people have Internet access, which changes the ways of relationship and communication. Digital technologies emerged as a new space of communication, sociability, organization and also a new market for information and knowledge [7]. Thereby, many possibilities arise for adopting resources and strategies for this new socio-cultural scenario. However, due this large number of possibilities, more complicated become the ways of task monitoring and performance evaluation, mainly in the areas of business and education.

In any context, human performance depends on various factors and varies depending on the person and the situation. This could be influenced also by factors of the environment where the person is inserted. This explains why even the best employees or students may not deliver good results. When the quality of services is lacking or the average class grade is unsatisfactory, it is usually because people are not performing as expected, and this can occur for a variety of reasons, for example: value of rewards, individual effort and the perception of the individual place [4].

Performance evaluation and task monitoring could be great allies to empower, motivate and reward employees or students. Through this practice, it is possible to focus peoples' activities properly, align individual goals with the organizational ones, joining performance at work with the medium-term objectives and strategies of the corporation and to maximize the potential of individuals and the team to benefit the organization. The evaluation allows the identification of potentialities and make a career progression, and also, alert those who are not doing well. It is feasible to provide in- formations to evaluators about their progress and identification of strengths and weaknesses.

The adoption of a system for constant monitoring and evaluation could help with the class follow-up. With these mechanism, it is possible to provide a formative evaluation. The term "formative" means that the information will be collected during the education process [5]. Evaluation, in turn, aims to "delineate, obtain and pro- vide information for making educational decisions" [12, p. 338]. The main idea of a formative evaluation is to check results progressively, in order to adjust learning activities to improve student attainment.

This way, we propose a gamified system for activity monitoring and performance evaluation. Gamification is a technique to stream- line the learning process or training, and make tedious or repetitive tasks more enjoyable [13]. Consists in the use of game elements in varied contexts, for purposes that are not exclusive of entertain-ment. Through this practice, it is possible to improve performance, promote socialization, and generate a sense of achievement. When properly used, gamification is an ally that gives positive returns by keeping focus, and at the same time, entertainment. We choose this technique to motivate and engage the users of the system.

The evaluation will be through the Learning Vectors Model (LV). The LV Model is a methodology which uses geometric representations of the performance, which makes possible the classification qualitatively and quantitatively [10]. It was originally created to help teachers, tutors and students of distance education. It allows semi- 
automatic evaluation. The evaluated ones have continuous feedback and grades are given from an association between one horizontal and one vertical component representing the positive and negative contributions of the interactions between the class. This model has been chosen for being a dynamic tool, since it allows the semi-automatic evaluation.

\section{Related Work}

Some works in the area of Educational Computing have been studied to solve problems related to performance evaluation and follow-up of tasks. Here we list the ones which used the Learning Vectors Model and gamification in order to obtain different objectives.

\subsection{Work based on the LV Model}

The LV Model focuses on the interaction of the teaching group with the virtual learning environment. It was created to support and encourage formative evaluation and automate the qualitative / quantitative follow-up of students. The research based on the LV Model has used this methodology to monitor and evaluate students in virtual learning environments. Here we list two works which used the LV Model with different approaches and objectives.

Sales et al [11] addresses possible impacts which could influence online avoidance. It was compared two methodologies: spread- sheet and the LV Model. For the monitoring of activities, it has been established that one class would be evaluated by digital spread- sheet, available only at the end of the course. The other class would be evaluated by the LV Model. It was noticed that, with the constant monitoring of the activities through the LV Model, it is possible to infer changes in the avoidance rate. The changes in the evaluation methodology, of summation for formative, contributed to lower student dropout rates.

The work seen in Gonçalves et al [6] presents an application of the methodology known as Instruction by Peers, associated with the non-linear evaluation of the LV Model, to the Forum "Questions and Answers" of the Virtual Learning Environment Moodle. The authors justify their choice of the LV Model saying that it facilitates pedagogical interventions and motivate those involved. The result is a computational mechanism based on a nonlinear formative assessment model, implemented in an online course with wide acceptance.

\subsection{Work based on Gamification}

Gamification is used in different areas to influence behaviors and practical results. There are a fair variety of games with different purposes, not only entertainment, as Serious Games or Digital Game
Based Learning (DBGL). Works which uses this methodology applies gamification with different objectives, mainly in order to motivate the users. Here we list the ones faced to the education field.

In Carvalho et al [3], the development of a game centered on mythical characters of Brazilian folklore is discussed. Although the authors do not use the term "gamification", they talk about the use of game elements with learning purposes. They introduce Folclórica, a 2D single player puzzle game that places the student in contact with different Brazilian myths. In their research, they asked students about the Brazilian folklore and realized that they know more about foreign myths, as Thor, Odin or Anubis. The authors also made questions about the game and collected suggestions for improvement.

The work seen in Villalba et al [14] describes the application of the game Yumi Yumi with five-yearold children to assesses the effects regarding gender equality. It has been used the Engineer-

\subsection{Comparison}

As seen in the previous subsections, the LV Model and gamification has been used in educational computing with purposes of formative evaluation and motivation, but have never been used together. Also, they were not used for task monitoring and performance evaluation. In order to make a fair comparison, we set four criteria that differentiate our work from the related ones: (1) if the work makes use of the LV Model, (2) if the work used gamification, (3) if the objective was to evaluate the performance and (4) if the work makes task monitoring. Table 1 shows the comparison between our work and the related ones.

Table 1. Related work and comparison

\begin{tabular}{|l|c|c|c|c|}
\hline \multicolumn{1}{|c|}{ Reference } & $\mathbf{1}$ & $\mathbf{2}$ & $\mathbf{3}$ & $\mathbf{4}$ \\
\hline Sales et al [11] & $\mathrm{x}$ & & $\mathrm{x}$ & \\
\hline Gonçalves et al [6] & $\mathrm{x}$ & & $\mathrm{x}$ & \\
\hline Carvalho et al [3] & & $\mathrm{x}$ & & \\
\hline Villalba et al [14] & & $\mathrm{x}$ & & \\
\hline Pedreira et al [9] & & $\mathrm{x}$ & & $\mathrm{x}$ \\
\hline Our proposal & $\mathrm{x}$ & $\mathrm{x}$ & $\mathrm{x}$ & $\mathrm{x}$ \\
\hline
\end{tabular}

As seen in Table 1, the LV Model is addressed in an educational context, and has showed itself as an alternative way for qualitative and quantitative evaluation. The works analyzed in this section which uses the LV Model is faced to evaluation. The gamified systems have learning purposes. but do not meet performance evaluation, neither task monitoring. Our system is the only gamified faced to performance evaluation and task monitoring that uses the LV Model. 


\section{Background}

This section discusses the theoretical basis used in this work. The concepts about the LV Model for a non-linear formative evaluation are discussed. Also, we present some settings related to gamification and the use of game elements in a non-game context.

\subsection{Learning Vectors Model}

The Learning Vectors Model is a qualitativequantitative method- ology of non-linear evaluation, that allows constant monitoring for the evaluated ones. LV Model focuses on the interaction of the group in the virtual learning environment, mainly in the use of distance activities. The LV Model is based in dynamic systems and uses vectors and numerical equations in a two-dimensional way, determined by projections on the Cartesian axis. These values represent the bipolarity between the qualitative and quantitative dimensions [10]. Visually, the vector is indicated by an arrow that rotates counterclockwise and allows users to check how his learning is going. Figure 1 shows the vectors of the LV Model.

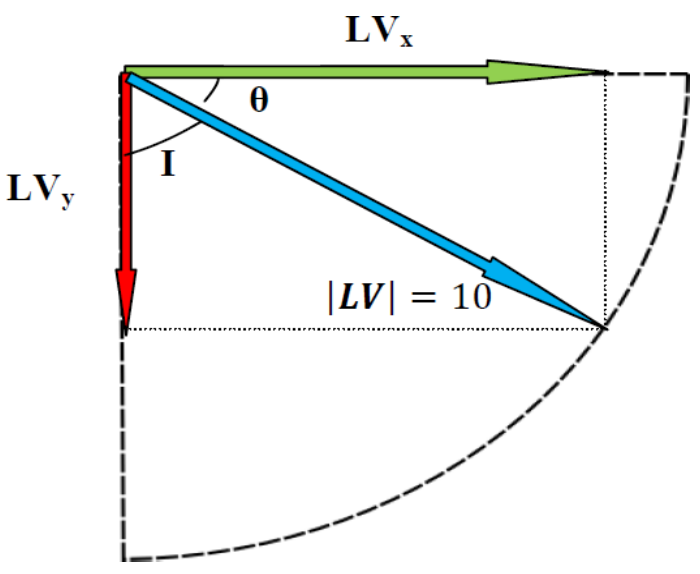

Figure 1. Graphic representation of the vectors of LV Model [10, p. 88]

Through the vectors, the scores obtained by synchronous and asynchronous activities, are presented graphically by means of a vector and numerical values. The vectors have a fixed module of 10 units, with directions starting at the angle $\theta=$ 90 (lowest score), until the value of $\theta=0$ (highest score). The geometric representation consists of the axes $\mathrm{LVx}$, horizontal projection, and $\mathrm{LVy}$, vertical projection. These are related to positivity and negativity factors, respectively. The module of the component LVx is the score obtained by the user in different fulfilled activities. Equation 1 shows how the value of LVx is obtained.

$$
\mathrm{LVx}=10 \times \cos [(-12 \alpha+\mathrm{I})]
$$

The calculation of component LVX takes into account the variable $\alpha$, value of the standard learning step, stipulated in $7,5 \alpha$, and the variable I, for the total angular variation $(\Delta \mathrm{T})$ of the vector and function of the $\alpha$ angle. The movement of the vector depends on the variable I and $\alpha$. The value of $\alpha$ was determined as 7,5 $\alpha$ for dividing the angle of $90 \hat{A} z ̌$ in equal parts. The vertical component LVy, related to the negativity of the performance of the user, is determined by the Equation 2.

$$
\operatorname{LVy}=10 \times \operatorname{sen}[(-12+\mathrm{I})]
$$

From the positivity and negativity factors, similar to bipolar dimensions, it is defined a non-linear pedagogical metric called $\beta$ Factor, which indicates the level of the user. This factor is related to the qualitative nature of the LV Model, and involves the good and bad results of the contributions of students in tasks performed in the virtual environment. Equation 3 shows the calculation of the $\beta$ Factor.

$$
\beta=\text { Positivity } / \text { Negativity }
$$

The evaluators have access to an iconic representation associated with the scale of qualitative statements (Likert scale) to assign value to the evaluated ones' performance. The LV Icons, similar to emojis, can transmit sentimental aspects, since they are graphical representations of emotions. They present categories associated to the degree of what have been presented, as well as the level of interaction with their peers. Table 2 shows the values

\begin{tabular}{|c|c|c|}
\hline Icon & Description & SC* \\
\hline & Very good: in-depth reflections & 4 \\
\hline & Good: good reflections & 3 \\
\hline & Regular: medium reflections & 2 \\
\hline & Weak: empty content reflections & 1 \\
\hline & $\begin{array}{l}\text { Unsatisfactory: person who } \\
\text { assumes a passive position }\end{array}$ & 0 \\
\hline & $\begin{array}{l}\text { Neutral: messages or files that do } \\
\text { not bring contribution }\end{array}$ & - \\
\hline
\end{tabular}
of each LV Icon that will make part of the equations

Table 2. Description of LV Icons

The values of the LV Icons are called Step Coefficient, and they are important for the calculation of the quantitative grade, influencing the 
variable I. The neutral icon does not increment the note but serves to compute the presence of the person in the activity. It is also important to point out that each type of LV activity has a different calculation that better fits this one.

The LV Model was evaluated and validated and it was verified the effectiveness of use as a continuous process of formation. The degree of satisfaction of teachers, tutors and students was verified too. The use of the methodology proposed in this system collabo- rates to differentiated actions throughout the teaching and learning process. The implementation and testing of the LV Model proves that it is possible to construct a model that relates numeric values with the subjective scale of mentions, and at the same time, presenting qualitative and quantitative values.

\subsection{Gamification}

Gamification is a definition used for the application of game elements in contexts that are not just for entertainment. It is used to encourage behaviors and practical results. The origin of gamification is linked to studies in the area of Human-Computer Interaction, in which the user interface could be informed by other design practices. These ideas have generated interest in research related to the user' experience, particularly in themes involving games for purposes, in which the player is encouraged to solve several tasks using the game interface as a support.

Classic definitions of game say that these are characterized by a clear system of rules and encourage competition between actors, in view of specific goals or outcomes. Although games are the basis for the understanding of gamification, this term cannot be defined as a methodology to create games, but rather the application of game mechanisms in diverse contexts to reach a certain goal, engaging and motivating the participation of those involved. The application of gamification involves the experience of users, the intention to arouse positive emotions, to explore personal aptitudes and to bring rewards to fulfill tasks [13].

Characteristics presented in games comprise a set of indissociable elements, not always explicitly structured. They consist of a collection of elements found in most games, but not necessarily at all. There are the classification of the elements according to Werbach \& Hunter [15], in which the authors list three kinds of elements: dynamics, mechanics and components. Figure 2 shows the organization of the game elements according to the degree of abstraction, arranged in decreasing order.

Dynamic elements represent the highest level of abstraction and consist of themes in which the game develops, e.g. the narrative, the relationship between the players and the progression. The mechanics are related to the orientation of the players' actions, as the evaluation, feedback, challenges, rewards and acquisition of re- sources. The components are at the most concrete level and de- scribe specific applications viewed and used in the game interface, as ranking, scores, missions, time, unlockable content, among others. These elements can take various combinations, that is, an element can be both dynamic and mechanical. Combining game elements effectively is the main task of a gamified project.

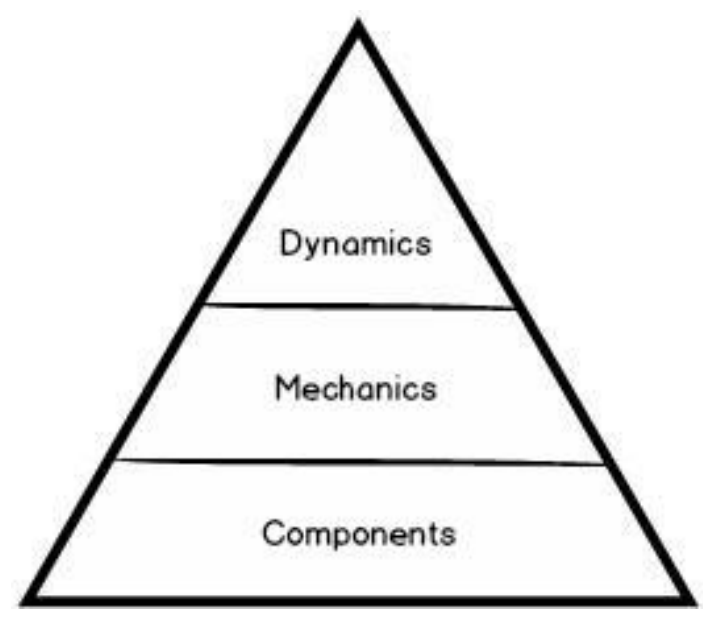

Figure 2. Classification of game elements Adapted from [15, p. 82]

Games aim to achieve four motivating axes: competition, learning, escape from reality and social interaction [13]. One of the elements for building good mechanics is the correct definition of a reward system. The prize at the end of a completed task is the main reason that leads players to continue in a game until the end. Another element that keeps the participant engaged in achieving the objectives is feedback, so the player keeps aware of his performance and in what stage he is. Also, gives a sensation of progress. Small rewards throughout the process are also important to stay focused.

Gamification has been recognized as a pedagogical practice that can qualify the teaching and learning processes. This is an emerging phenomenon which arises from the popularity of digital games in the cyberculture. Its capacity to motivate actions, solve problems, learning in various areas of knowledge could be a great allied in the processes of collaboration and cooperation, as well as to develop other skills relevant to the context of cyberculture [8].

\section{Design and development of the system}

The idea of a system for performance evaluation and task monitoring came out from the intention of put two methodologies with similar objectives together, helping the control and evaluation of students or employees. Through this system, it is 
possible to man- age activities, as well as the evaluation of those involved at the end of the process. The system gives support to the monitoring of the users' scores, helping managers with the follow-up of members and their evolution. It may also recognize those who are not making progress, or have regressed, and thus be able to verify the causes of these.

We used the Learning Vectors Model associated with gamification to encourage people to achieve the yield of high performance teams. The LV Model helps the constant monitoring and classification, providing a formative assessment. We aim to assist in the interactions between those involved in various tasks, to pro- vide follow-up to evaluators and evaluated ones. At the end of the interaction and evaluation processes, it is expected that our system could improve the performance and motivation of the team.

\subsection{Learning Vectors adapted to the system}

The idea is to calculate scores and levels with the formulas of the LV Model. The result obtained in the system is made by the Learning Vectors Model adapted to our objectives. As the LV Model, we aim a non-linear evaluation. The scores will be given by the same formulas of the LV Model to calculate the positivity and negativity, and the values for $\mathrm{LVx}$, which indicates the positivity, are used for the punctuation. For better understanding, the points will be called P. It is possible to observe the relations of the equations to the values obtained in Equation 4. The value of $\mathrm{P}$ initially is zero and then the actual $\mathrm{P}$ count plus the value obtained by the calculation of the previous value of $P$.

$$
\mathrm{P}=\mathrm{Pi}+(10 \times \cos [(-12 \alpha+\mathrm{I})])
$$

Scores are obtained by calculating LVx, while total points are the sum of all scores obtained. The ranking depends on the scores, but consists only of the sum in the week, since it is updated weekly. This can also help in accomplishing more tasks, since more tasks results in more evaluations and, consequently, higher scores. Higher punctuation gives more chances of joining the first positions of the ranking. It is possible to access the average of those evaluated at the time of reporting, as well as the history of scores, what could be considered as a formative assessment.

The $\beta$ Factor is the indicative of whether or not to level up. As in LV Model, the $\beta$ Factor is calculated by dividing positivity by negativity. At the beginning, passing the phase is easier, but with each level reached, the difficulty increases. The levels are numerically divided, for example, level $1,2,3, \ldots, n$. There is no limit number. To increase the level, the score obtained must always be the double of the previous one. The calculation of the number needed to reach levels depends on other variables, as unlock badges and keep reasonable valuations. The following algorithm shows the logic be- hind the calculation of levels, with $\mathrm{cl}=$ current level, $\mathrm{nl}=$ next level (all integer numbers), and a boolean lu = level up.

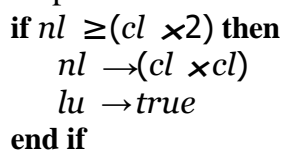

The variable lu begin as false and change to true if the value of $\mathrm{nl}$ is achieved, so the user advances to a higher level. The value of $\mathrm{nl}$ is determined by multiplying the current level by twice these value, e.g. if the value of $\mathrm{cl}$ is 2 , the value of $\mathrm{nl}$ is $\mathrm{x} 2$, it means that the person has to obtain at least a 4 in the next evaluation, determined by the $\beta$ Factor. The nl value receive the double of $\mathrm{cl}$ if the user level up and it serves as the new parameter to be reached. At the beginning of the game, the first evaluation of the $\beta$ Factor is stored as the first value of $\mathrm{cl}$, and then, the user has to obtain always the double of the ancient value. For example, if the first evaluation of the user is 1 , the second one has to be 2 to level up, the next has to be 4 , and so on.

The LV Model was chosen as a mechanism to support dynamic evaluations and to provide a constant feedback to those involved in an educational process, as well as to verify negativity and positivity. We aim to unite valuation with gamification and encourage users to adopt positions that improve their performance, but in a fun way. Through these resources, it is assumed that, if the user had in hand the mechanisms necessary to know their own performance, those evaluated will identify factors that hinder and those that improve performance and take measures to modify or maintain the progress of the task resolutions.

\subsection{Learning Vectors adapted to the system}

Gamification is used in our system to keep people focused and engaged in a given task. These concepts could help with various tasks. These could also clarify the perception of the employer about their own role within the environment. The most common elements in systems that use gamification are scores, badges and ranking. According to [15], these are used more commonly for being powerful, practical and relevant to get desired results. This way, these elements have been chosen to be the main motivating points of our system. Following the classification of game elements according to the degree of abstraction, the game elements selected can be divided can be seen in Table 3 .

The elements used in our system are related to types of behavior motivators. Dynamic elements represent interactions between players. Chats and 
alerts are proposed in order to encourage the team to have more connectivity and socialization. Another dynamic element is the progress bar of the tasks, providing follow-up and also showing the progression in the accomplishment of the missions. Mechanic elements are those related to player orientation. The mechanics are composed by feedback and rewards. These mechanisms are associated with the component elements, with achievements, levels, points and ranking. Conquests are visual representations of some achievement achieved in the gamification process. They help to set goals, mark achievements, serve as signs of progression and may indicate status.

Table 3. Kinds of game elements of the system

\begin{tabular}{|l|l|}
\hline \multicolumn{1}{|c|}{ Type } & \multicolumn{1}{c|}{ Element } \\
\hline Dynamics & Progress bar, chat, alerts \\
\hline Mechanics & feedback, rewards \\
\hline Components & badges, levels, scores, ranking \\
\hline
\end{tabular}

The elements used in our system are related to types of behavior motivators. Dynamic elements represent interactions between players. Chats and alerts are proposed in order to encourage the team to have more connectivity and socialization. Another dynamic element is the progress bar of the tasks, providing follow-up and also showing the progression in the accomplishment of the missions. Mechanic elements are those related to player orientation. The mechanics are composed by feedback and rewards. These mechanisms are associated with the component elements, with achievements, levels, points and ranking. Conquests are visual representations of some achievement achieved in the gamification process. They help to set goals, mark achievements, serve as signs of progression and may indicate status.

The levels are related to the evaluations: more completed assignments generate more good grades to the users, and the more they gain levels, which becomes increasingly difficult as the progress. The score is another component of the system and is connected to levels and to the ranking. The points will be given by the evaluators through the LV Model and serve as a parameter for the placement in the ranking, for level up and to provide a basis for unlock the achievements. Figure 3 shows the badges of the system.

These elements are important to positively influence the performance of the users and lead them to adopt positions similar to those of highperformance teams. The aim is to encourage healthy competition among users and constant assessment of tasks, thus helping supervisors gain control over the activities of the company, as well as employees will follow up on how they are doing. It is expected that the use of the system improves the understanding

that the employees have of their importance within the organization and that improve their yields from the feedbacks of the evaluators.

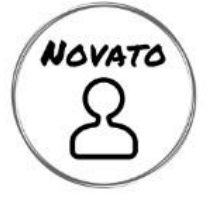

(a) Badge "Novato" (newbie)

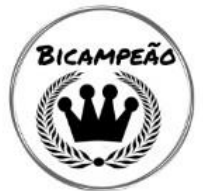

(c) Badge "Bicampeão" (two time champion)

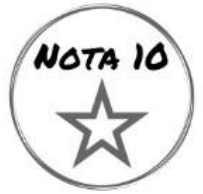

(e) Badge "Nota 10" (grade 10) (f) Badge "Subiu de nível" (upgrade)

Figure 3. Badges of the system

\section{Evaluation and Preliminary Results}

To ground our assertion, we developed a web system and adapted our proposal to the corporate area called Process Planning and Institutional Evaluation (PIPA). We choose to make the test with managers and employees to verify if it could be used in a learning environment but in the context of business environment, where there is more charge. Corporate strategies should contribute to the achievement of the objectives of companies, and, consequently, guarantee their sustainability. Our objective is to keep the employees engaged and committed to their own income, also to give support to managers to monitor the performance of the members of the team.

\subsection{Aspects of implementation}

The development of PIPA was planned with several studies of which technologies to use and what the final appearance would look. Firstly, technical details were considered, such as the language that would be used, the extensions and libraries that would help the system functionalities and which ones would better fit the proposal. The system was built using the PHP programming language, the script language JavaScript, HTML 
markup language and the CSS styling language. PHP was initially chosen because it was the same language used for programming the LV Model. In addition, MySQL database was used and some libraries, as Bootstrap ${ }^{1}$, to make the application responsive, and $\mathrm{RGraph}^{2}$ to generate dynamic charts.

The architecture of the program follows the model known as three-tiered application (3-Tier), architectural style in which the system is organized into three main layers [1]. The layers used for the architecture of PIPA are the user interface, the presentation screens that will make the interaction with people; the business layer, with the logic of the application; and the database layer, which will store score information, personal data, and employee appraisal history.

There are three user profiles: administrator, manager and user. The users can be enrolled in activities by managers and administrators, and can access the notes assigned to them, update the status of tasks and send files and comments. Managers are responsible for registering activities, recruiting users for them and doing the evaluation at the end. They will have access to the scores of the users. The administrator is the profile that will handle the system. The manager can do what a manager does, but it is also possible to register people and classify them into any of these categories.

The design of PIPA was inspired by the minimalist design, which has the least graphic resources and texts. It does not mean that it has little content, but rather broadens the essence of what is really important, to the point of making everything else expendable before the focus of creation [2]. The reason for choosing minimalist themes is to focus the attention of the users on the content, that is, tasks, and to divert the focus of graphic elements. The home page of the system can be seen in Figure 4. This screen contains the main information about the user, as his evaluation through the vectors of the LV Model, the ranking, the badges and the the pending tasks.

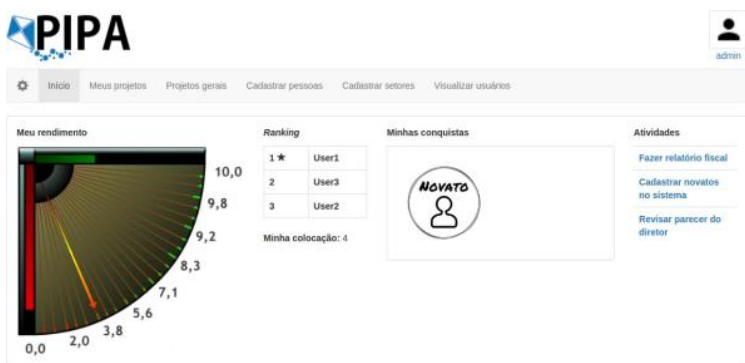

Figure 4. Page of the user of the system

\footnotetext{
${ }^{1}$ http://getbootstrap.com/

${ }^{2}$ http://www.rgraph.net/
}

As seen in Figure 4, there are the representation of the current evaluation through the vectors of the LV Model. The ranking only shows the first three places. This is to avoid unhealthy competition and possible constraints of people who are not well placed. The position of the user is only shown to him and to his superior if the person is not among the top three. The container in the middle shows the badges of the user and the one positioned to the right shows the tasks which are in progress.

The page of projects shows the tasks of the person is registered as a member of a team or individually. This screen shows the number, unique code of each registered task, name, type, priority and whether it is completed or not. This information is previously registered by the manager who opened the task in the system. The types are related to the sectors to which it is related, such as administrative or financial. Figure 5 shows the page of the user. Only the people involved in these tasks could monitoring the progress of these. The manager and the administrator are the only ones which access of the tasks in the system.

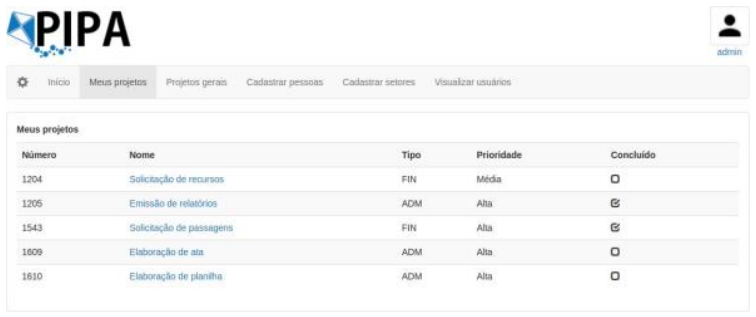

Figure 5. Page of the user's projects

In the projects tab, it is possible to have an overview of everything what is being produced in the company, not only the processes assigned to the user. This page is important for monitoring the projects of the colleagues. Authors are the people who registered the activity in the system, it means, users with a manager or administrator profile. 'Assigned' is related to the person who is intended the task.

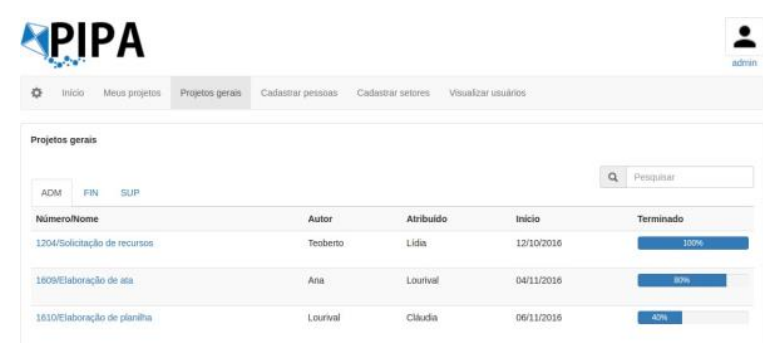

Figure 6. Page of general projects

The system has been made available to the general community, especially to the target audience of developers and people who want to use PIPA to manage their activities in the company. The 
repository used to store the code, as well as a version controller, was GitHub ${ }^{3}$ and can be accessed in this link: https://github.com/Cacais/PIPA.

\section{Evaluation}

For the field research, we choose a company of representation of seals and enclosures for the mineral water and beverages segment. It consists of a microenterprise with 7 employees, a receptionist, an accountant, two proprietary partners and three representatives working externally, located in Passaré neighborhood of the city of Fortaleza, Ceará. The test period was a little more than a month in the first quarter of 2017. A week before the start of the tests, a meeting was held with the owners and employees for explanations of how to use the system, and then began to use it. In this context, the system could be an ally to control the activities of everyone who works in person, but especially those who work outside.

We scheduled a day for installation of the program and explanation of how to use it for all employees. On that day, employees who work externally were also present, and it was possible to teach everyone. A local server was used inside the company and was explained individually as access, register tasks, evaluate and monitor their performance through the system. They all collaborated and seemed excited to use it. After the training, the contacts were left in case any of the employees had any questions or to solve technical problems.

The system was used for a month, more precisely thirty-six days. At the end of the process, another meeting was scheduled for delivery of software evaluation forms and feedback. Two forms were applied: one for self-evaluation and another for supervisors to evaluate the employee's income. The questionnaires had objectives and subjective questions. It was made clear to the participants that the procedure would be anonymous, with the sole purpose of raising data for an academic research, and that colleagues would not have access to the answers. At the end of this period, the forms were collected.

The forms contained questions about the adequacy of the software to the environment, employee satisfaction and performance improvement. Thus, the evaluation models were divided into two parts: one for self-evaluation, aimed at employees in general, including the owners; and one for employee evaluation. The purpose of this would be to analyze whether employees perceived changes in their income and whether the bosses noticed it. All answered the self-assessment questionnaires, while only the owners answered the evaluation of the results of their collaborators.

\subsection{Preliminary results}

The results of the questionnaire are organized together with the questions to which they refer. In general, the system improved employee performance. When asked about this, they said they were able to pay more attention of how the tasks were going and that the employees were more focused. As for the ease of evaluation, they felt a bit of difficulty at first, but with little time have been able to evaluate. The results can be checked as follow.

\subsubsection{Questionnaire of the evaluators}

1. Did the employees obtain improvement in income through PIPA?

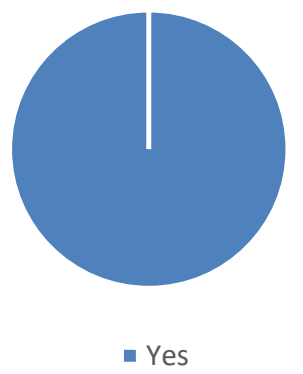

2. The level of difficulty of evaluating employees by PIPA was:

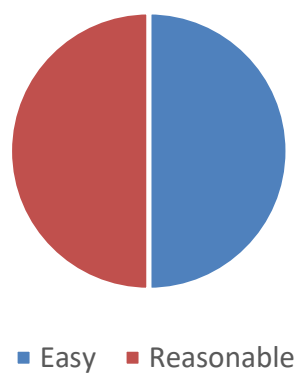

3. Did the monitoring of the activity of the employees by PIPA helped the company?

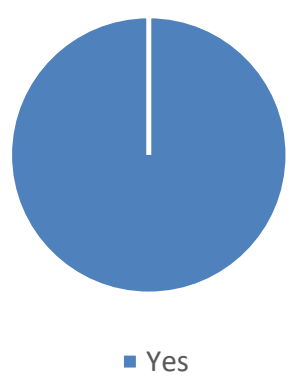

4. Did you use to evaluate employees beforehand by any other method?

\footnotetext{
${ }^{3}$ https://github.com/
} 


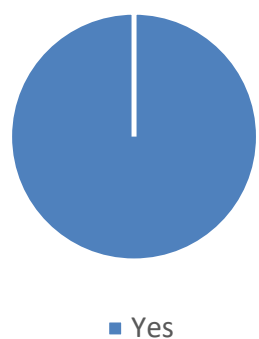

As it could be observed, the acceptance of the system was good and there are not problems of adaptation of users with the system. There was no difficult in making the evaluations through PIPA, according to the answers to the second question. The managers did not use to evaluate the employees before (question 4) and they said that the monitoring of tasks helped the company.

\subsubsection{Self-assessment questionnaire.}

1. In a general way, how do you evaluate your experience with PIPA software?

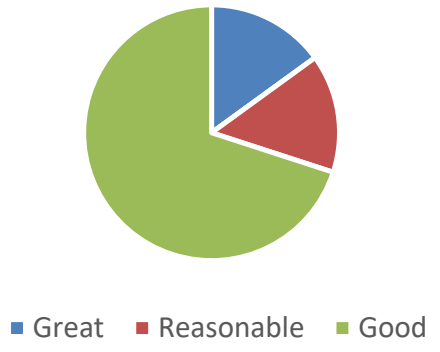

2. In your opinion, do your performance improved with PIPA?

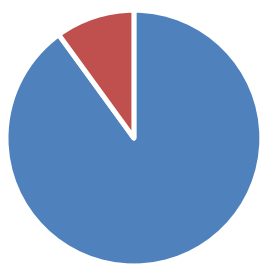

- Yes - Not sure

3. Do you think your interaction with others improved using PIPA?

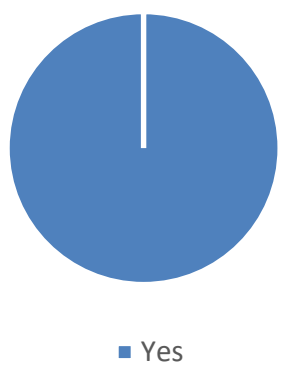

4. Was the evaluation by PIPA a positive, negative or neutral factor?

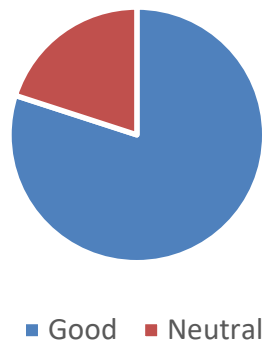

The objective of the self-assessment questionnaire was to verify in the customer's view whether it meets the desirable characteristics for a system. According to the responses of those involved, the system improved the communication between the members of the team. In general, the users liked the experience. As for performance, the software remained stable and there were no technical problems throughout the experiment. The suggestions for improvement were:

- $\quad$ Put a repository for digital files (.doc, .pdf)

- Improve navigation. It's a little confusing

- Could be created an application to access the mobile system

- Maybe put more pictures

- The system could issue reports

The questions were elaborated to verify the length of the work objectives. From the responses of the users, it was possible to conclude that the system was able to motivate and interact among the members of the company. It is important to say that there was not a lot of people in this preliminary test, but it was possible to verify the acceptance of the system in a real context. Furthermore, the comments and suggestions to improve our system consist of valuable contributions for further implementations.

\section{Conclusion and Future Work}

With the changes in the habits of the population and the influence of cyberculture in many aspects of the routine, it is important to look for new ways of performing tasks in order to achieve the objectives. It is not different with the task monitoring and performance evaluation. Our proposal is to apply the LV Model and gamification in order to improve results in a learning environment, helping with the class follow-up. With these mechanisms, it is possible to provide a formative evaluation.

Testing process was very helpful in uncovering the strengths and weaknesses of the system as well as collecting suggestions for improvements. The objectives we had at the beginning were verified and 
it can be concluded that, for this preliminary evaluation, the system was carried out in a profitable way, fulfilling the established goals. According to the answers of the questionnaires applied, it is presumed that the one planned in the beginning was fulfilled. In the future, we want to test our system in a school to analyze how students and teachers will behave and how will the acceptance.

Our system encourages the improvement of performance, which will be stimulated through gaming elements to have more productivity, since mechanisms will be added for constant checking of evaluations and feedback. It is also intended to improve the monitoring of what is being produced in the company, in order to identify armful factors, and thus be able to take preventive measures. This way, both evaluators and evaluators gain in the process. In future works, it is hoped to improve the visual aspect of PIPA, making it more attractive and intuitive to the public and improving the user experience in using it. It is also one of the future objectives to use Fuzzy Logic for the LV Model.

\section{References}

[1] P. Bourque, R. E. Fairley, et al. Guide to the software engineering body of knowledge (SWEBOK (R)): Version 3.0. IEEE Computer Society Press, 2014.

[2] W. Carrion. Design para web designers: princípios do design para web. Rio de Janeiro, 2008.

[3] L. F. Carvalho, D. A. Barone, M. Bercht, H. Prendinger, A. Timm, and I. C. Moura. Teaching brazilian folklore through videogames: a way to motivate students. In Conferência Internacional em Informática na Educação - TISE, volume 20, pages 385-396, 2015.

[4] I. Chiavenato. Gestão de pessoas. Elsevier Brasil, 2008 .

[5] B. N. Flagg. Formative evaluation for educational technologies. Routledge, 2013.

[6] A. J. Gonçalves, J. L. L. Cunha, and G. L. Sales. Concepção do fórum $\mathrm{p} \& \mathrm{r}$ lv: avaliação formativa da aprendizagem. RENOTE, 14(1).

[7] P. Levy. Cibercultura. Editora 34, 2010.

[8] C. Martins and L. M. M. Giraffa. Gamificação nas práticas pedagógicas: teorias, modelo e vivências. Education, 4(2):6, 2015.

[9] O. Pedreira, F. García, N. Brisaboa, and M. Piattini. Gamification in software engineering-a systematic mapping. Information and Software Technology, 57:157$168,2015$.

[10] G. Sales. Learning Vectors (LV): um modelo de avaliação da aprendizagem em EaD online aplicando métricas não-lineares. $\mathrm{PhD}$ thesis, Tese Doutorado.
Departamento de Engenharia de Teleinformática. Universidade Federal do Ceará. 2010. 239f, 2010.

[11] G. L. Sales, E. A. M. Leite, and C. R. Joye. Gerenciamento da aprendizagem, evasão em ead online e possíveis soluções: Um estudo de caso no ifce. RENOTE, 10(3), 2012.

[12] D. Unwin and R. McAleese. The encyclopaedia of educational media communications and technology. Greenwood Pub Group, 1988.

[13] Y. Vianna, M. Vianna, B. Medina, and S. Tanaka. Gamification inc.: como reinventar empresas a partir de jogos, 2013.

[14] K. Villalba, A. Ocsa, J. Vera, L. Cruz, and A. Mogrovejo. Efecto de videjojuego yumi yumi en la perspectiva de género de niños y niñas de 5 años.

[15] K. Werbach and D. Hunter. For the win: How game thinking can revolutionize your business. Wharton Digital Press, 2012.

\section{Acknowledgements}

We would like to thank the Postgraduate Program in Computer Science of IFCE (PPGCC) and the Foundation to Support the Scientific and Technological Development of Ceará (FUNCAP). 